\title{
Water, sodium, potassium and chlorine balance during late pregnancy and early lactation in high-yielding dairy cows under winter Mediterranean conditions
}

\author{
N. Silanikove ${ }^{1}$, E. Maltz ${ }^{2}$, A. Halevi ${ }^{1}$ and D. Shinder ${ }^{1}$ \\ ${ }^{1}$ Institute of Animal Science \\ and \\ ${ }^{2}$ Institute of Agricultural Engineering, Agricultural Research Organization, Volcani Centre PO Box 6, \\ Bet Dagan 50250, Israel
}

\section{Introduction}

Water turn-over (WTO) rate in dairy cows is among the highest recorded in mammals (Shalit, Maltz, Silanikove and Berman, 1991). Likewise, secretion of sodium $(\mathrm{Na})$, potassium $(\mathrm{K})$ and chlorine $(\mathrm{Cl})$ in milk markedly increases their output, so that in some cases the amount of $\mathrm{Na}$ and $\mathrm{Cl}$ secreted via milk is larger than that lost in urine (Shalit et al., 1991). The balance of water, $\mathrm{Na}, \mathrm{K}$ and $\mathrm{Cl}$ in dairy cows was studied under hot Mediterranean summer conditions (Shalit et al., 1991). It was found that at initiation of lactation, when dry-matter intake (DMI) is still limited and hot weather obstructs its rapid increase, the current National Research Council (1989) recommendations for providing these ions as concentration in the diet were not met. The negative balance of $\mathrm{Na}, \mathrm{K}$ and $\mathrm{Cl}$ was associated with marked reduction of their loss in excreta, particularly $\mathrm{Na}$ and $\mathrm{Cl}$. The deficiency in $\mathrm{Na}, \mathrm{K}$ and $\mathrm{Cl}$ might have limited sweat secretion, and hence reduced thermoregulation efficiency of the cows and perhaps even negatively affected milk production (Shalit et al., 1991). As the increase in milk secretion in early lactation is faster than the increase in DMI, it was suggested that initiation of lactation probably is, in itself, a factor that may cause ion depletion (Shalit et al., 1991); this assumption was examined in the present study.

\section{Material and methods}

During the winter, water, $\mathrm{Na}, \mathrm{K}$, and $\mathrm{Cl}$ balance was measured in six polyparous Israeli Holstein cows at 2 weeks before calving (period 1), 2 weeks post partum (period 2), and 7 weeks post partum (period 3) as described by Shalit et al. (1991). Average night and day temperatures were $12^{\circ} \mathrm{C}$ and $14 \cdot 2^{\circ} \mathrm{C}$ respectively and relative humidity 0.85 to 0.93 . Data were analysed with cow, period and their interaction as the independent terms in the model. Statistical significance $(P<0.05$ or better) was assessed by the contrast routine.

\section{Results}

Live weight, DMI, milk yield and body temperature

Live weight was 654,550 , and $550 \mathrm{~kg}$ in periods 1, 2, and 3, respectively and milk yield was 29.4 and $41.5 \mathrm{l} /$ day in periods 2 and 3 respectively. There were no notable fluctuations in rectal body temperature between the morning, noon and evening within each period; the temperature of the cows in the three experimental periods was approximately $38 \cdot 6^{\circ} \mathrm{C}$.

Water balance

WTO rate was 2.65 and 3.29 times greater in periods 2 and 3 than in the pre-partum period (Table 1). Drinking water accounted for proportionately about

Table 1 Water balance ( $k g /$ day) in six cows two weeks before calving (period 1), 2 weeks post partum (period 2) and 7 weeks post partum (period 3)

\begin{tabular}{lccccccc}
\hline & Drinking & Within foodt & Total intake & In milk & Urinary & Faecal & RCW \\
\hline Period 1 & $36 \cdot 2^{\mathrm{a}}$ & $4 \cdot 8^{\mathrm{a}}$ & $41 \cdot 0^{\mathrm{a}}$ & & $11 \cdot 7^{\mathrm{a}}$ & $18 \cdot 7^{\mathrm{a}}$ & $10 \cdot 6^{\mathrm{a}}$ \\
Period 2 & $87 \cdot 3^{\mathrm{b}}$ & $21 \cdot 4^{\mathrm{b}}$ & $108 \cdot 7^{\mathrm{b}}$ & $34 \cdot 9$ & $11 \cdot 8^{\mathrm{a}}$ & $25 \cdot 3^{\mathrm{b}}$ & $36 \cdot 9^{\mathrm{b}}$ \\
Period 3 & $106 \cdot 6^{\mathrm{b}}$ & $28 \cdot 4^{\mathrm{c}}$ & $135 \cdot 0^{\mathrm{c}}$ & $37 \cdot 0$ & $15 \cdot 4^{\mathrm{b}}$ & $36 \cdot 1^{\mathrm{c}}$ & $41 \cdot 4^{\mathrm{b}}$ \\
MCV§ & $21 \cdot 0$ & $3 \cdot 4$ & $10 \cdot 2$ & $6 \cdot 4$ & $3 \cdot 0$ & $5 \cdot 9$ & $14 \cdot 5$ \\
\hline \hline
\end{tabular}

$\mathrm{a}, \mathrm{b}, \mathrm{c}$ Within rows, means having different superscript differ at $P<0.05$.

+ Moisture plus metabolic, metabolic water was calculated assuming $1 \mathrm{~kg} \mathrm{H}_{2} \mathrm{O}$ per $1 \mathrm{~kg}$ OM digested.

$\ddagger \mathrm{RCW}=$ Respiratory-cutaneous water output, calculated as total intake minus milk, urinary and faecal loss.

$\S \mathrm{MCV}=$ Mean critical value for differences between periods. 
0.9 of the WTO rate during the pre-partum period and for 0.8 during periods 2 and 3 . Loss of respiratory-cutaneous water (RCW) was the main component of the water output, accounting for proportionately 0.25 of the WTO rate pre-partum and about 0.34 in periods 2 and 3. Loss of RCW in the lactating cows was linearly and positively related to DMI (no. $=12, R^{2}=-0.78, P<0.004$ ), WTO rate (no. $=12, R^{2}=0.97, P<0.0001$ ), and negatively to milk yield (no. $=12, R^{2}=-0.75, P<0.006$ ).

Water loss in faeces was the third largest avenue of loss, accounting for proportionately 0.23 and 0.27 of the WTO rate during lactation (periods 2 and 3, respectively) and for 0.46 pre-partum. Faecal water excretion was linearly related to DMI (no. $=18, R^{2}=$ $0.97, P<0.0001)$, WTO rate, and free water intake (FWI) (no. $=18, R^{2}=0.93, P<0.0001$ ).

The water excreted via urine had the smallest contribution to total water loss, accounting for proportionately 0.29 of the WTO rate in period 1 , and 0.11 in periods 2 and 3 . Urinary water excretion was linearly and positively related to DMI (no. $=18, R^{2}=$ $0.55, P<0.01$ ), WTO rate (no. $=18, R^{2}=0.47$, $P<0.05$ ), $\mathrm{Na}, \mathrm{K}$ and $\mathrm{Cl}$ intakes (no. $=18, R^{2}=0.68$ to $0.70, P<0.001$ to 0.002 ), and excretions of urea, $\mathrm{Na}, \mathrm{K}$ and $\mathrm{Cl}$ in urine (no. $=18, R^{2}=0.48$ to $0.54, P<0.05$ to 0.01 ).

The milk free-water balance (MFWB) (WTO rate minus water excreted in milk) can be very efficiently predicted during summer and winter in lactating and non-lactating cows by the following equation: MFWB $=12.7+$ digestible energy intake (MJ $/$ day) $\times$ $0.13+\mathrm{RCW}$ loss (kg/day) $\times 0.97$ (no. $=33, R^{2}=0.96$, $P<0.0001)$.

\section{Ion balance}

Ion balance is represented by $\mathrm{K}$ balance (Table 2), the balance of $\mathrm{Na}$ and $\mathrm{Cl}$ showed a similar trend (data

Table 2 Potassium balance (meq/day) in six cows two weeks before calving (period 1), two weeks post partum (period 2) and seven weeks post partum (period 3)

\begin{tabular}{lccccc}
\hline \hline & $\begin{array}{c}\text { Total } \\
\text { intake }\end{array}$ & $\begin{array}{c}\text { In } \\
\text { milk }\end{array}$ & Urinary & Faecal & Retention \\
\hline Period 1 & $2693^{\mathrm{a}}$ & & $2583^{\mathrm{a}}$ & $397^{\mathrm{a}}$ & -288 \\
Period 2 & $3219^{\mathrm{a}}$ & 1746 & $1796^{\mathrm{b}}$ & $611^{\mathrm{a}}$ & -925 \\
Period 3 & $4763^{\mathrm{b}}$ & 1847 & $2176^{\mathrm{ab}}$ & $1201^{\mathrm{b}}$ & -461 \\
MCVt & 619 & 360 & 596 & 299 & 630 \\
\hline \hline
\end{tabular}

$a, b, c$ Within rows, means having different superscript differ at $P<0.05$.

$+\mathrm{MCV}=$ Mean critical value for differences between periods. not presented). As a result of the increase in DMI in period 3, total $\mathrm{K}$ intake in this period became significantly higher $(P<0.05)$ than in periods 1 and 2 . Urine $K$ excretion accounted for proportionately $0.96,0.56$, and 0.46 of total $\mathrm{K}$ intake in periods 1,2 , and 3 , respectively.

The ratio between milk $K$ excretion and total $K$ intake was similar to that of urine $\mathrm{K}$ excretion, and accounted for proportionately 0.54 , and 0.34 in periods 2 and 3 , respectively. The amount of $\mathrm{K}$ excreted via milk was similar in periods 2 and 3 . Faecal $\mathrm{K}$ excretion accounted for proportionately $0.15,0.19$, and 0.25 of total $K$ intake in periods 1,2 , and 3 , respectively. The amount of $K$ excreted during lactation (periods 2 and 3) was significantly $(P<0.05)$ higher than that pre-partum (period 1$)$.

$\mathrm{K}$ balances ranked in the order period $3>2>1$ $(P<0.05)$, being negative in periods $1(-0.11$ of the total intake), $2(-0.29$ of the total intake, and -0.62 of the milk free intake), and 3 ( -0.10 of the total intake. There were relatively large differences between the three periods in the average value; however, due to the large standard deviations these differences were not statistically significant.

\section{Conclusions}

The present study indicated that in addition to the two well known factors that dictate FWI and WTO rate in dairy cows, namely DMI and milk yield. RCW loss also becomes a significant factor in cows yielding $40 \mathrm{l} /$ day, even under temperate environmental conditions. This is most likely a result of activation of sweating in response to the large increment in the internal heat production. The present results also support the conclusion that DMI is the major limiting factor in the ability of the cows to satisfy their needs for $\mathrm{Na}, \mathrm{K}$, and $\mathrm{Cl}$ in early lactation. The cow's demand for $\mathrm{Na}, \mathrm{Cl}$, and, particularly, $\mathrm{K}$, cannot be satisfied completely by the current NRC (1989) recommendations. A deficiency in these ions may limit the ability of cows to produce maximal amounts of milk and may be involved in complications typical to the early stages of lactation.

\section{References}

National Research Council. 1989. 6th rev. ed., updated 1989. National Academy of Science, Washington, DC.

Shalit, U., Maltz, E., Silanikove, N. and Berman, A. 1991. Water, sodium, potassium and chlorine metabolism of dairy cows at the onset of lactation in hot weather. Journal of Dairy Science 74: 1874. 